obstruction from some such cause as the above. But none of these changes have been found in every case, and therefore the following view is held :-

(3) That the obstruction is due to arrested or maldevelopment of the kidney. The frequent association with other malformations is held to support this view, as well as the fact that hereditary and family cases have been recorded. This arrest might prevent junction between uriniferous tubules and pelvis being established. Ribbert holds that since the kidney develops from two anlagen-(a) the urinary portion (cortex and glomeruli) and (b) the conducting portion (the straight tubules)-failure of the parts connecting these (namely, the convoluted tubules) to develop would cause cyst formation, and that these cysts are of two kindsthose of the glomeruli and those of the extremities of the collecting tubules. In adults, at any rate, the retention is produced by chronic interstitial inflammatory processes in the region of the pelvis, calyces and medullary portion, leading to distension and obliteration of the uriniferous tubules (Senator, Morris, Garceau).

(4) The theory of maldevelopment or arrested development with subsequent new growth upon this (Garceau).

Clinical classification of cases (Senator). A. In the foctus. - This condition causes difficulty in parturition, stillbirth or death soon after birth from interference with the action of the diaphragm or from complications from the other malformations.

B. In the adult.-Group I.: A total absence of symptoms. Death from other causes and polycystic disease of the kidneys only revealed at necropsy. Group IT.: Cases showing symptoms of renal disorder-i.e., urinary symptoms, but these not characteristic of any definite condition. Group III.: In these there is a renal tumour. In Lejars's figures there were only 18 such out of 62 cases. (Senator.) In most cases the enlargement of the kidneys is insufficient for it to be detected during life.

Characters of the swelling.--This resembles hydronephrosis, but is usually bilateral. Fluctuation less usual, and the condition is usually bilateral.

Pain.-This, the most prominent feature of the second stage, may be slight or severe, present or absent. Very occasionally there are paroxysms like those of renal colic. (Senator.)

Characters of the urine. - This is variable and may be (a) normal in quantity and composition, $(b)$ scanty and of low specific gravity, $(o)$ occasionally neutral or alkaline, $(d)$ abundant, with or without albumin, or containing blood or rosettes resembling leucin.

Other observers have divided the condition into stages: thus Stages I., II., and III. But this is not a practical division clinically, even if it be correct, for the reason that most cases do not appear to follow "stages" in any way that can be discovered during life. "Edema is occasional, cardiac hypertrophy usual, and the case may resemble one of chronic interstitial nephritis" (Senator). "Uræmia is the usual termination." "The general condition may remain undisturbed or may deteriorate." "Cachexia is occasional, but fever rare" (Senator). "The course extends over years, but lacks uniformity in different cases." "Among the complications are: suppuration of cysts, calculus, hydronephrosis, and tuberculosis" (Garceau). "The onset is insidious and duration over years" (Senator, 20 years; Lejars, 15 years)

Our second case falls into Group $I_{\text {, }}$, and our first case into Group III., of the clinical classification of cases suggested by Senator. And the maintenance of good health in this case for six years with only one such kidney seems the more remarkable, since it is stated by authorities (e.g., Senator) that by the time the tumour is obvious the course is usually comparatively short, for the reason that so little renal tissue is by that time left for work.

Adelaide.

UNIVERSITY OF JuNDON, UNIVERsity CoLlege. -A course of four lectures on the Physiology of Vision and Colour Vision will be delivered by Dr. F. W. Edridge-Green on Wednesdays, at 5 P.M., beginning Feb. 19th. 'The lectures will be illustrated by experiments and demonstrations. They are free to qualified medical men on presentation of their card.

\section{NOTE ON A CASE OF}

\section{CHRONIC INTERNAL HYDROCEPHALUS.}

BX JAMES RAE, M.A., M.D. ABERD.,

ASSISTANT MEDICAL OFFICER, PARK hOSPITAL FOR CHILDREN, HITHF GREEN.

THE finding of a clot in the torcular herophili in association with hydrocephalus has apparently not been recorded, and the fact may justify an account of such a case.

The patient, a boy aged 4 years 10 months, was the tenth of a family of 13 . The father was healthy; the mother " had a cough" and had been an out-patient at a chest hospital for several years. Three children died from wasting and "consumption of the bowels"; one from convulsions one from diphtheria, and one was stillborn. The patient himself was subject to convulsions during his first year. $\mathrm{He}$ began to take notice and to talk at about the usual age and had measles and whooping-cough. Shortly before his fourth birthday he seemed to become stupid, and at this time his parents thought his head was enlarging. He was admitted to Lambeth Infirmary on Dec. 14th, 1911, and transferred to the Park Hospital for Children, Hither Green, on Nov. 27th, 1912. On admission his head measured $22 \frac{3}{4}$ in. in circumference, and the anterior fontanelle $2 \frac{1}{4}$ in. laterally. The chest had marked rickety deformities, with an angular projection on the ninth rib of each side just outside the niyple line. The arms were spastic and the hands clenched. The frontal and the right angular veins were very prominent, and when the child cried the external jugular veins became half an inch in diameter. On the evening of admission signs of pneumonia appeared on the right side, subsequently extending. Death took place on the tenth day after admission.

Neoropsy. - A post-mortem examination was made 24 hours after death. The right lung was in a state of red hepatisation; the lower lobe of the left lung showed a few scattered tubercles. Four bronchial and two mesenteric glands were enlarged and caseating, the largest being $\frac{3}{8}$ in. in diameter. No other tuberculous foci were seen in the body. There were no pleural adhesions, and not more than 2 drachms of clear yellow fluid in the pericardial cavity. When the meninges of the brain were opened a large quantity of clear fluid escaped, and continued to drain away when the brain was removed. The cerebrum weighed $31 \frac{1}{2} \mathrm{oz}$, and when opened out measured $13 \frac{3}{8} \mathrm{in}$. from edge to edge. Its cortex was $\frac{3}{8}$ in. thick, and the corpus callosum $\frac{1}{8}$ in., the fornix being a mere film. The cornua of the lateral ventricles had the following depths : posterior, $1 \frac{1}{1}$ in. ; anterior, just under 1 in. ; lateral, only $\frac{1}{1}$ in. The cerebellum, medulla, and pons together weighed $3 \frac{3}{4} \mathrm{oz}$. The veins of the cerebellum and those passing through the right foramen cæcum were much enlarged and tortuous. The Sylvian veins also were distended, particularly on the right side. The lateral sinuses measured $1 \mathrm{in}$. in diameter, the occipital sinus $\frac{5}{8}$ in. at its posterior end, and the internal jugular veins $\frac{3}{4}$ in.

The torcular herophili contained a pyramidal blood clot, lying with its apex towards the straight sinus. When fresh the clot weighed just under $\frac{1}{4} \mathrm{oz}$, was $1 \frac{1}{8}$ in. high, and $1 \mathrm{in}$. across its base. Its outer surface was a dark golden yellow, except for a deep crimson layer at the base, 3/16 in. deep. The cut surface was visibly laminated, deep pink in the centre, growing paler towards the periphery.

This clot is now in the Museum of the Royal College of Surgeons of England, and Mr. S. G. Shattock has kindly sent me the following report on it: "As viewed in section the clot is at one pole of a bright red colour; the rest, and by far the chief portion, is devoid of colour, and has a flexible, finely sponge-like character. Histologically the uncoloured portion consists of a somewhat open felt or tangle of fibrin filaments. Scarcely any red cells are present in the meshes, but a moderate number of polymorphonuclear leucocytes and lymphocytes are distributed through it. There is no free blood pigment. The red end of the clot consists of recent blood, but this merges into the structure just described, the number of red cells diminishing in the meshes of the fibrinous stroma, until practically none are to be encountered. There are no vessels in any part of the coagulum, and no fibroblasts-i.e., no organisation is in progress."

As bas been stated above, no similar case appears to have 
been recorded. D'Astros, in the section of his monograph which deals with renous obstruction, does not mention the formation of such clots. Browning $\dagger$ has reported the discovery of an organised thrombus, $\frac{1}{3}$ in. long, lying in the straight sinus, with another in the longitudinal sinus (? superior or inferior) in a less acivanced condition. His patient was a girl aged 6 , who died three months after hydrocephalus was first observed.

Hither Green, S.E.

\section{THE ACTION OF SCHARLACH R UPON X RAYED SKIN.}

\section{By J. O. WAKELIN BARRATT, M.D., D.Sc. LoNd. \\ (From the Cancer Research Laboratory, The University, Liverpool._Mrs. Sutton Timmis Memorial.)}

IN previous communications the condition of mitosis in epithelium caused to proliferate by the action of Scharlach $\mathbf{R}^{1}$ has been studied, and also the course of events following upon implantation of such epithelium. ${ }^{2}$ The present paper deals with the effect of injection of Scharlach $R$ into the skin of the ear of the rabbit exposed, 2 to 15 months previously, to the action of $X$ rays. In such cases the full destructive effect of the $X$ rays has been produced and the skin has again passed into a stationary condition.

It will be of advantage to study first the change produced by Scharlach $R$ in the $X$ rayed skin of the ear when the amount of destruction effected by the action of $\mathrm{X}$ rays has not been sufficient to produce complete disappearance of all the appendages of the skin. These changes are illustrated in

FIG. 1.
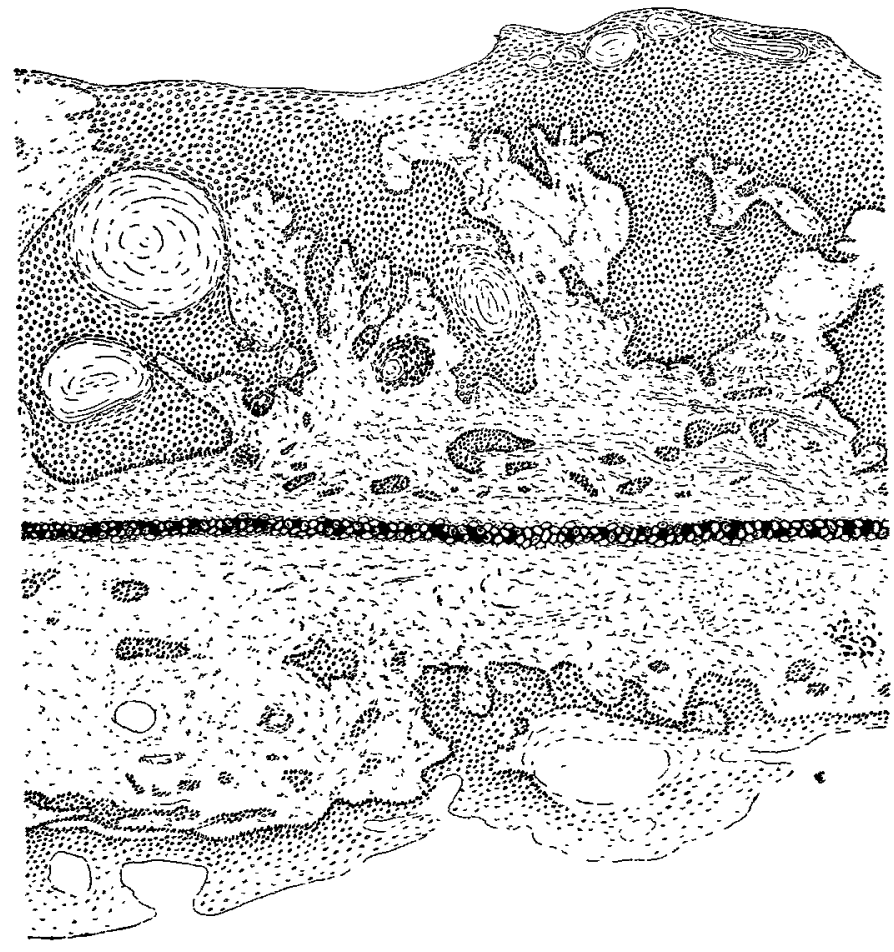

$$
{ }_{0 m i m}
$$

(The scale of Figs. 2 and 5 is the same as that of Fig. 1.)

Seation of ear of rabbit $\mathrm{A}$, exposed to the action of $\mathrm{X}$ rays 15 months previously. Scharlach $\mathbf{R}$ dissolved in olive oil was injected beneath the skin of the outer surface of the ear and later a portion of the injected area was removed for sectioning. Considerable epithelial proliferation has occurred chiefly, but not exclusively, in the epithelium of the outer surface of the ear. Both surfaces are irregular. The nuclei of the cutis vera are increased in number. The upper border of the section represents the outer The upper $\times 30$.

* D'Astros : Les Hydrocéphalies, Paris, 1898

$\dagger$ Browning: New York Journal of Nervous and Mental Disease, 1887. vol. Xiv., p. 260

1. J. O. Wakelin Barratt: On Mitoses in Proliferating Epithelium, Proceedings of the Royal Society, 1907, Series B, vol. Ixxix., p. 372

2 J. O. Wakelin Barratt: Implantation of Actively Proliferating Epithelium, ibick., p. 546 .
Figs. 1 to $4,{ }^{3}$ which are made from two rabbits (A and $B$ ) similarly treated. The changes induced by the action of $\mathrm{X}$ rays in these two rabbits were of long standing, having: been set up 15 months previously, so that at the time of injection of Scharlach $R$ about 80 per cent. of the hairs had disappeared from the portion of the ear $\mathrm{X}$ rayed, those remaining being free from pigment, and shorter and finer than those present before the application of $\mathrm{X}$ rays. The skin of the ear was thinner than normal, pale and smooth, presenting a somewhat scarred aspect and exhibiting irregular areas of increased pigmentation alternating with areas nearly free from pigment. These changes were more marked on the outer aspect of the ear than on the inner.

On microscopic examination of the $X$ raved skin before the injection of Scharlach R (Figs. 2 and 4) it was found that a marked degree of destruction of the hair follicles had occurred. This was greatest in rabbit $\mathbf{A}$ (Fig. 2). 'The hair follicles remaining were diminished in diameter and in length, the former change affecting chiefly the deeper

FIG. 2.

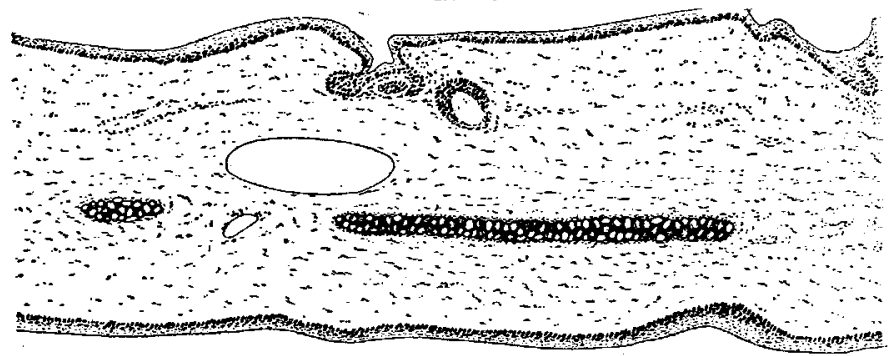

Section of ear of rabbit $A$, exposed to the action of $X$ rays 15 months previously. The portion of the ear represented months previously. The portion of the ear represented. made but is outside the area injected with Scharlach R The hair follicles have been, for the most part, destroyed by the action of $X$ rays. The surface epithelium is markedly pigmented, especially on the outer aspect of the ear. A large vein is seen above the cartilage, which does not extend completely through the section. This section should be
compared with that given in Fig. $1 . \times 30$.

portion of the follicles, which were not unfrequently converted into thin cord-like structures. Most of the papillæ of the hair follicles had disappeared, and, as a rule, hair shafts were absent. In the upper part of the follicles a lumen was present containing epithelial scales, the accumulation of which sometimes caused distension of this part of the follicle. In the lower part of the follicle, in most cases, no lumen was recognisable and the follicle appeared to be solid, being made up of small prickle cells. The mouths of the hair follicles were observable as large openings, usually filled with loose horny epithelium. Sometimes the horny epidermis at, or just below, the mouths of the hair follicles had accumulated to such an extent as to give rise to epithelial collections reaching a millimetre or more in diameter. The sebaceous glands had in part disappeared. The hair follicles were more affected on the outer surface of the ear than on the inner. The surface epithelium shown in Fig. 2 is of about the normal thickness, but is pigmented to an excessive degree. The cutis vera, owing to the small size and number of hair follicles, is thinner than normal, and appears to be made up to a greater extent than usual of connective tissue. The blood-vessels are less numerous than usual; in consequence of this the cellular elements of the corium are fewer than usual.

In rabbit $\mathrm{B}$ (Fig. 4) the destruction of the hair follicles is less marked. It is little evident in the skin of the inner surface of the ear (lying below in the figure) in which the hair follicles mostly contain hair shafts of fair size, but in the outer skin of the ear the hair follicles are affected to a greater degree, fewer hair shafts being seen. The epithelial distension of the mouths of the hair follicles referred to above is exhibited in a marked degree. The surface epithelium differs from that in Fig. 2 in not being pigmented to an excessive degree. The number of cells in the corium is not diminished to the same extent as that in the previous animal.

The injection of Scharlach $R$ into the skin of the rabbit's ear, exposed, as above described, to the action of $\mathrm{X}$ rays in.

3 The tissues from which the sections were made were hardened in Zenker's solution and stained by Heidenhain's iron-alum hæmatoxrlin method or with thionin and orange $G$. 